\title{
AVALIAÇÃO DO PROCESSO DE GESTÃO NA IMPLANTAÇÃO DE PROCESSOS INOVADORES NA FACULDADE DE MEDICINA DE MARÍLIA: ASPECTOS DA RESILIÊNCIA DOCENTE E DISCENTE
}

\author{
Rinaldo Henrique Aguilar da Silva*
}

Recebido em: 07 de abril de $2009 \quad$ Aprovado em: 25 de abril de 2009

*Pós-doutorando em Ensino Superior em Saúde pela Universidade Federal de São Paulo (UNIFESP), Mestre e Dr. em Genética e Evolução, Especialista em Administração Universitária e Gestão Acadêmica, Prof ${ }^{\circ}$ da Faculdade de Medicina de Marília (Famema).E-mail: aguilar@famema.br

Resumo: Este artigo apresenta e discute os resultados de uma pesquisa avaliativa, com enfoque qualitativo, durante o processo de gestão na implantação de métodos ativos de ensino-aprendizagem. Foi verificado como se comportam gestores, docentes e discentes e a relação com a efetividade destes processos. A análise apontou como núcleos temáticos o entendimento do que é gestão participativa, resultados esperados com a implantação da gestão participativa e aprendizagens institucionais em relação à implantação da gestão participativa.

Palavras-chave: Avaliação. Educação superior. Gestão Participativa.

\section{EVALUATION OF THE MANAGEMENT PROCESS IN THE IMPLEMENTATION OF INNOVATIVE PROCESSES IN THE MEDICAL SCHOOL OF MARÍLIA: ASPECTS OF TEACHER AND STUDENT RESILIENCE}

\begin{abstract}
This essay presents and discusses the results of a qualitative evaluation of the management process during the implementation of active teaching-learning methods. The following issue was checked: the behavior of management, teachers and students and its relation to the effectiveness of the process. The analysis pointed out the following themes relative to shared management: understanding of the concept, the expected results and institutional learning in relation to its implementation.
\end{abstract}

Keywords: Evaluation. University education. Shared Management.

\section{Introdução}

Em consonância com sua história, a Faculdade de Medicina de Marília (Famema) mantêm-se em permanente transformação e avaliação, permitindo uma construção coletiva e democrática de seus currículos, afinada às necessidades e requerimentos da sociedade e atualizada em função da evolução da ciência e da tecnologia.

Esse permanente trabalho, de auto-avaliação e desenvolvimento curricular têm-nos encorajado e sinalizado a necessidade de um engajamento ainda maior. Para tanto, realizamos reformas curriculares e de gestão buscando um desenvolvimento integral da instituição. 
Estas mudanças implementadas em 2003, nos cursos de Medicina e Enfermagem, fazem parte do Projeto Famema século XXI e propõem um currículo orientado por competência e baseado em Necessidades de Saúde da população.

O programa dos dois cursos é centrado no estudante, baseado na comunidade e na aprendizagem significativa, desafia os estudantes a descobrirem os caminhos que lhes permitam aprender a aprender e construir sua formação profissional.

Em relação à gestão é importante considerar que para o desenvolvimento de um currículo inovador, que trabalha com metodologias ativas de aprendizagem, fez-se necessária a reformulação das estruturas e modelos tradicionais de gestão.

Diversos estudos sobre tendências na gestão têm mostrado que práticas gerenciais tradicionais não respondem mais às necessidades de melhor desempenho e satisfação. E, portanto, na Famema que adotou modelos de ensino/ aprendizagem inovadores, o processo de gestão buscou privilegiar a eficácia das decisões e sobretudo a auto aprendizagem organizacional. Este sistema exigiu uma reformulação do desenho organizacional buscando estratégias integradoras e mais participativas (AGUILAR-DA-SILVA; TSUJI, 2006). Nesta perspectiva, "participar" significou literalmente "fazer parte", implicando na livre escolha e permitindo às pessoas obterem mais conhecimento e comprometimento nos assuntos e questões fundamentais para o desenvolvimento Institucional. "Comprometimento” referindo-se além do estado de participação, a um sentimento de total responsabilidade na criação de uma visão compartilhada.

As Instituições de Ensino Superior (IES) no país estão tradicionalmente organizadas nos modelos de gestão democrática, formalizada através de órgãos representativos internos, mas apresentando reduzido grau de exercício da democracia direta pelo conjunto das categorias funcionais que as integram.

Além disto, parece haver uma insatisfação em relação aos processos educacionais vigentes e seus resultados, tendo em vista o movimento da sociedade, da criação das Diretrizes Curriculares Nacionais (BRASIL, 2001) e do Sistema Nacional de Avaliação (SINAES), pelo Ministério da Educação. (BRASIL, 2004)

A pertinência das universidades e instituições de ensino superior, em termos de sua função face à mudança social e da sua relação interativa com o mundo do trabalho, tem sido apontada como uma das estratégias principais para responder aos desafios do mundo em transformação. (UNESCO, 2000)

Diante desta situação e contrariamente à idealização das IES como geradoras do conhecimento, encontramos frequentemente lugares dominados por uma racionalidade instrumental, causando um desconforto existencial àqueles que aspiram uma universidade mais humana e menos técnica. 
Devemos considerar que as IES apesar de muitas vezes se configurarem como empresas, não podem ser tratadas como tal no que se refere à gestão. Elas necessitam de uma base filosófica distinta para a discussão de seus processos e não simplesmente uma transposição de métodos.

Dibella e Nevis (1999) chamaram de aprendizagem organizacional todos os tipos de atividades que ocorrem em qualquer etapa do processo de mudança. Consideram também que aprender significa ganhar experiência, competência e evitar a repetição de enganos.

Para Kim (1993), maior aprendizagem organizacional corresponde a maiores índices de sucesso na realização de novas ações com menor resistência pelos indivíduos.

Há, portanto, que educar para o exercício da liberdade consciente, para a autotranscendência, o que significa favorecer ao longo das experiências de ensino-aprendizagem o desenvolvimento da autoconfiança; estimular no educando o exercício da escolha, e, sobretudo a descoberta e aceitação de sua singularidade e unicidade. Há que formar pessoas críticas e responsáveis e não indiferentes ou conformadas com o mundo em que vivem; formar pessoas conscientes de seu espaço de criação e de sua capacidade de transformação da sociedade. (CAMPOS, 1995)

Utilizando, portanto as premissas da gestão do conhecimento de:

a) promover inovação a partir do estímulo ao potencial presente na organização e da circulação do conhecimento;

b) desenvolvimento da capacidade de inovar da organização e

c) ações em rede voltadas para a melhoria do potencial interno de produção e codificação de conhecimento, os processos decisórios tornam-se mais transparentes e participativos legitimando ações e o trabalho de coordenação entre os diversos níveis de hierarquia.

Para que isso ocorra não podemos deixar de considerar a necessidade de se trabalhar a resiliência frente aos processos de mudança, sobretudo àqueles considerados inovadores.

$\mathrm{Na}$ Famema o coletivo institucional vem focalizando e refletindo sobre esta necessidade e produzindo documentos que apontam alguns dos problemas no âmbito do processo de gestão nos diferentes cenários que conformam as práticas de saúde e educacionais. Tais documentos foram desenvolvidos a partir das oficinas de trabalho de "Gestão participativa", realizadas durante o Fórum 2008 de Desenvolvimento Curricular da Famema. 


\section{Objetivo}

Verificar através da análise avaliativa como se comportam os gestores, docentes e discentes frente à implantação de Metodologias Ativas de Ensino Aprendizagem e sua correlação com a efetividade dos processos inovadores de gestão acadêmica.

\section{Método}

\subsection{Natureza do estudo}

Tratou-se de uma análise de pesquisa avaliativa, o que segundo Contrandriopoulos e outros (1997), significa "examinar através de um procedimento científico as relações que existem entre os diferentes componentes de uma intervenção" e para tanto serão utilizadas as abordagens de pesquisa quantitativa e qualitativa, as quais são perspectivas complementares quando se pretende aproximar de uma realidade com a finalidade de conhecê-la. (MINAYO; SANCHES, 1993)

\subsection{Campo do estudo}

O campo é o recorte espacial que corresponde à abrangência, em termos empíricos, ao objeto de estudo (MINAYO, 1992), este compreende o contexto onde se desenvolve o objeto, sendo o espaço onde serão obtidos os dados empíricos sobre o mesmo.

Assim o campo determinado para este estudo foi onde se desenvolveram as oficinas de Processo de Gestão e do Trabalho em Saúde durante o Fórum 2008 de desenvolvimento Institucional da Famema.

\subsection{Análise dos Dados}

O método utilizado para a análise baseou-se na análise de conteúdo, modalidade temática, com ênfase na abordagem qualitativa de pesquisa social (BARDIN, 1979; MINAYO, 1992; GOMES, 2005). Esta técnica consiste em descobrir os "núcleos de sentido" que compõe a comunicação e cuja presença, ou freqüência de aparição pode significar alguma coisa para o objetivo analítico escolhido. (BARDIN, 1979)

\section{Resultados}

Foi realizada a leitura de todos os instrumentos preenchidos durante a oficina, buscando uma compreensão global, na qual se privilegiou não apenas 
o conteúdo, como também sua lógica. Em seguida através de confrontos de diferentes instrumentos foram identificados núcleos de sentido ou eixos que estruturavam os depoimentos, em torno dos quais se agrupavam características comuns (GOMES, 2005). As temáticas identificadas, em torno das quais os dados foram, analisados e discutidos são:

\section{1 entendimento do que é gestão participativa}

A totalidade dos depoimentos de gestores, docentes e estudantes retratou uma imagem satisfatória do entendimento do conceito de gestão participativa, o que reforça a positividade da mudança implementada na instituição.

Na visão dos estudantes uma gestão participativa está retratada na "quantidade" de participantes nos órgãos colegiados da instituição "[...] é um modelo onde as diretrizes institucionais são geradas a partir da participação efetiva de grande número de estudantes." Além disto, é ressaltada a necessidade de que o poder decisório seja compartilhado igualmente entre docentes e estudantes "na gestão participativa o peso do voto nas decisões institucionais deve ser o mesmo para professores e alunos". Para os docentes e gestores a gestão participativa aparece fortemente com o foco da integração "[...] é desenvolvida com a integração dos setores envolvidos com o objetivo de desenvolver o propósito de um objetivo".

As dificuldades no processo de comunicação estão presentes na fala de docentes e estudantes e apontam esta como a mais importante característica do processo "Os processos de gerenciamento carecem de boa comunicação docente o que dificulta a implantação da gestão" "[...] é necessário otimizar os processos de comunicação institucional melhorando a capacidade de ouvir, dialogar e delegar poder de decisão".

Consideramos estas características apontadas como uma riqueza das experiências vivenciadas até agora compondo um quadro motivador e facilitador do processo de mudança.

\subsection{Resultados esperados com a implantação da gestão participativa}

Verificamos nos depoimentos que a gestão vem sendo considerada uma ferramenta que norteia a produção de novos conhecimentos, possibilitando um olhar diferenciado para a realidade, constituindo-se em um potente instrumento para adequação da Instituição: 
[...] possibilita o desenvolvimento e implantação de uma tecnologia avaliativa de processos considerando os aspectos que contemplam o arcabouço delineador de qualidade" "apontará para as fortalezas e pontos que requerem atenção e proporcionará subsidios para a readequação do processo analisado [...] visto que estamos em um momento político favorável à implantação de novas tecnologias de gestão.

Para os estudantes a gestão "poderá fornecer elementos para melhor compreensão dos processos, propiciando potencializar as estratégias ao encontro da realidade dos estudantes”.

\subsection{Aprendizagens Institucionais em relação à implantação da gestão participativa}

No tocante aos processos desenvolvidos na Instituição foi destacada a grande integração existente entre os cenários de ensino/aprendizagem e o modo através do qual eles se interagem:

[...] a organização das séries propicia uma maior descentralização na tomada de decisões [...] existe uma boa integração entre as disciplinas e as instâncias decisórias.

[...] a representatividade estudantil nos processos acadêmicos demonstra a efetividade da processo de gestão [...]

A principal fragilidade encontrada nos discursos refere-se à pouca sistematização dos processos de gestão:

[...] fazemos de modo empírico, sem nos preocupar com a profissionalização dos gestores" "os estudantes muitas vezes ainda nem sabem gerir sua vida e seus estudos, como podem ajudar a gerir uma instituição? [...] os estudantes precisam ser preparados para participar dos processos decisórios, caso contrário podem continuar resistentes ao processo de mudança.

\section{Discussão}

A noção de resiliência tem origem na Física e na Engenharia e nessa área é associada à capacidade máxima de um material de suportar tensão sem se deformar de maneira permanente. Há vinte anos, tem sido também usada de uma maneira mais abrangente para significar uma habilidade pessoal de voltar ao estado normal de saúde ou de espírito após períodos de doenças ou dificul- 
dades de qualquer tipo, muitas vezes, ligada ao conceito de invulnerabilidade às adversidades.

Assim, no âmbito desta discussão, há professores universitários e discentes que apresentam maior resistência aos fatores agressores encontrados na prática da gestão, criando alternativas para controlar os desafios e responder às dificuldades, reagindo às adversidades e mostrando-se capazes de recuperação das agressões sofridas, e por isso, têm seu stress diminuído.

Se por um lado isto pôde ser observado na Famema, por ocasião da implantação dos processos, com gestores, professores e discentes mais resilientes e participativos, pudemos também constatar que muitos se sentem agredidos, buscam mecanismos de proteção e deixam de participar.

Conforme Yunes (2001), os principais mecanismos de proteção contra o risco são: reduzir a exposição da pessoa à situação estressora, reduzir as reações em cadeia geradas pela situação de risco, garantir a auto-estima e a auto-eficácia através da realização de tarefas bem sucedidas em um clima de afeto e segurança, e criar oportunidades para que a pessoa se adapte. Os mecanismos de proteção estão ligados ao modo como a pessoa lida com as mudanças em sua vida, ao sentido que ela atribui às suas experiências e à sua maneira de atuar diante das adversidades, podendo interagir com outros fatores de risco, tanto psico-sociais quanto genéticos. Entretanto, não podemos abordar a questão em termos de que a resiliência seja apenas conseqüência de características internas da personalidade do indivíduo, passíveis de serem construídas. Ao contrário, precisamos considerar os fatores ambientais e o contexto relacional e ressaltar a importância do suporte das relações de apoio incondicional para a promoção do sentimento de auto-estima e auto-eficácia. Enxergar a resiliência em termos individuais pode contribuir para rotular a vítima como fracassada e, desse modo, reforçar o desequilíbrio social vigente que não oferece oportunidades para que as pessoas se comportem de diferentes maneiras frente a uma dada situação, massificando atitudes e comportamentos.

Nesta direção, é na articulação entre a capacidade da pessoa criativa de inovar, de ser flexível, de ter uma boa imagem de si mesma, de associar idéias de diferentes formas e de ser persistente e a capacidade de tornar-se resiliente que buscamos, na aceitação do grupo de pertencimento, a chave para o desenvolvimento de professores mais seguros, mais sensíveis e mais equipados para agir na transformação de seu próprio ambiente cultural.

Para Alarcão (2001), hoje, ser professor pressupõe um conceito de formação permanente, contínua, especializada e em ação. Este perfil de formação inacabado traz consigo novas formas de trabalhar em equipe, de ser pró-ativo, de 
identificar as próprias necessidades de formação e os meios para consegui-la, de usar novas tecnologias e assumir riscos.

As políticas de Formação Permanente buscam atuar na formação e na gestão do trabalho pedagógico e em saúde; para tanto, deve envolver "mudanças nas relações, nos processos, nos atos de saúde e, principalmente, nas pessoas." (CECCIM; FEUERWERKER, 2004)

Para isso a Famema instituiu o Programa de Desenvolvimento Docente (PDD) que é o responsável pelo trabalho de capacitação docente institucional. Atua através de Educação Continuada e Educação Permanente, focalizando a construção de instrumentos pedagógicos e de uma cultura reflexiva que possibilitem docentes, comunidade acadêmica e rede de serviços comprometidos com a formação de profissionais na área da saúde, a releitura de suas concepções e práticas profissionais sob a luz das necessidades de saúde explicitadas pela sociedade.

Este programa tem como objetivo a desconstrução de representações internas e do processo de trabalho internalizado advindo do modelo biologicista a partir da confrontação de sua adequação frente às realidades do mundo do trabalho e assim, a transformação e construção de novas práticas pedagógicas que tenham maior potencialidade em assegurar a integralidade do cuidado às necessidades de saúde das pessoas (HIGA; ILIAS; FIORINI, 2007).

Para Campos (2000), o processo de trabalho apresenta uma dupla finalidade: produzir bens e serviços necessários ao público e cuidar da constituição do Sujeito e dos Coletivos. O trabalho significando não somente um meio para assegurar sustento material, mas também para a constituição das pessoas e de sua rede de relações: equipes, grupos, organizações, instituições e sociedades.

A aposta de Merhy (1997) é de que devemos tomar como desafio central a produção de uma reforma "publicizante” do sistema de direção dos serviços, que implique em uma “coletivização” da gestão dos processos de trabalho.

Historicamente pautada na administração científica, cabe à gerência institucional o papel de controlar e regulamentar o trabalho, através de normas administrativas e com padronizações técnicas. A crítica formulada a esta abordagem é que se retira do trabalhador a responsabilidade pela criação autônoma e desregulamentada, necessária para assegurar a qualidade em saúde (CAMPOS, 1997). O mesmo autor afirma que podemos verificar a impossibilidade deste controle total, pois os trabalhadores operam com suas subjetividades, com seu autogoverno, conseguindo burlar normas e trabalhar de acordo com sua própria consciência; porém esta autonomia não tem sido utilizada para construir projetos eficazes. 
Este desafio deve ser superado com trabalho contínuo e com participação coletiva. A Famema apesar de haver buscado modos de gestão mais participativos ainda enfrenta dificuldades como as apontadas pelos docentes e discentes no que se refere, sobretudo, aos canais de comunicação internos como foi explicitado durante a pesquisa avaliativa. Esta falta de comunicação pode fazer com que muitos sujeitos se sintam à margem da implantação dos processos. Isto fica evidenciado com o apontamento de que ainda existe pouca sistematização dos processos de gestão implantados até o momento.

Novas técnicas gerenciais criadas pelas Teorias da Administração das Organizações, supostamente potentes para lidar com os trabalhadores pouco produtivos e alienados, têm se mostrado insuficientes para erradicar o desinteresse, a alienação, o agir mecânico e burocratizado (CAMPOS, 1997). Este autor atribui que o algo mais é um pouco mais complexo do que uma simples tecnologia de gestão; há necessidade de instituir novas formas de governar os serviços públicos, e aposta na reordenação da distribuição de macro e micropoderes, ou seja, na criação de sistemas de gestão que permitam combinação de diretrizes consideradas como antagônicas, como a centralização e descentralização, autonomia da base e responsabilidade para com objetivos gerais da instituição, planejamento de metas e flutuações de demanda. Este processo exigiria uma flexibilidade doutrinária e operativa, um grau de democracia e de distribuição de poder que não fazem parte da nossa cultura (CAMPOS, 1994). Nesta direção, afirma que é possível revolucionar o cotidiano, ao se trabalhar com o pressuposto de que os mecanismos de dominação/exploração, os micropoderes, podem ser questionados durante a organização ordinária e comum da vida das instituições, sem que se tenha alterado o esquema mais geral de dominação no nível do Estado, da sociedade política e do mundo da produção. Ou seja, a instituição de novas relações dependeria de sujeitos capazes de gerir seu cotidiano, considerando as potencialidades e limites para a mudança, em um contexto de determinações histórico-estruturais.

Campos (1994, p. 67) conclui apostando:

[...] que o viver cotidiano não precisa ser aquele da repetição, da renúncia à autonomia e ao desejo; [...] que o trabalho pode ser um espaço para a realização profissional, para o exercício da criatividade, um lugar onde o sentir-se útil contribua para despertar o sentido de pertinência à coletividade, transcendendo o papel tradicional do trabalho que é de, quando muito, assegurar a sobrevivência e um determinado nível de consumo. Uma via para transcender a alienação social. Uma possibilidade em aberto. 
Partindo da construção teórica de Merhy (1997), podemos afirmar que no processo pedagógico, professores e estudantes produzem-se mutuamente, através de suas “subjetividades", de modos de sentir, de representar e de vivenciar as necessidades educacionais e tomar decisões acerca do projeto político a ser desenvolvido nas instituições, atuando na micropolítica do trabalho em saúde. Ao trabalhar a temática da micropolítica do trabalho vivo em saúde, Merhy (1997) nos proporciona possibilidades sobre a gestão do cotidiano em saúde, conforme aponta Campos (1997). Esta perspectiva nos remete a transitar da produção e cristalização da organização do trabalho em saúde para processos de mudanças que se caracterizam por novos espaços de ação e novos sujeitos coletivos, bases para redirecionar o sentido do cuidado de saúde. (MERHY, 1999)

Desta forma, na micropolítica do processo de trabalho, este está sempre em aberto, ou seja, passível de se analisar seu sentido e a maneira como está sendo gerido pelos trabalhos vivos que se cristalizaram, a fim de inventar novos processos de trabalho. Isto ocorre na medida em que se abrem fissuras nos processos instituídos, em que a lógica do processo de trabalho, bem como sua finalidade, são postos em xeque, incluindo a forma com que está sendo gerida pelos trabalhos vivos precedentes, que se cristalizaram.

Nesse sentido, Merhy (1997, p. 101) aposta

[...] na possibilidade de se constituir tecnologias da ação do trabalho vivo em ato e mesmo de gestão deste trabalho que provoquem ruídos, abrindo fissuras e possíveis linhas de fuga nos processos instituídos, que possam implicar a busca de processos que focalizem o sentido da "captura" sofrido pelo trabalho vivo e o exponham às possibilidades de "quebras" em relação aos processos institucionais que o operam cotidianamente.

Na perspectiva de gestão participativa, Campos (1997) afirma que o desafio estaria na adequada combinação de autonomia profissional com certo grau de responsabilidade para os trabalhadores. Não haveria uma combinação prioritariamente ideal, deveríamos buscar, em cada contexto, arranjos singulares articulados ao projeto político assistencial em curso. Este conceito vai ao encontro das propostas da Famema que busca a construção do conhecimento à partir das experiências prévias de cada sujeito, tomando cada um como parte do processo de construção das propostas institucionais.

Afonso (2005), ao discutir sobre as funções da avaliação, coloca que nas organizações, tanto de saúde como de educação, são os processos de avaliação, instrumentos de gestão importantes na estruturação das relações de trabalho e também funcionam quase sempre como instrumentos de controle e de legitimação profissional. 
Portanto, vem ao encontro da idéia da avaliação formativa, entendendo que o professor não reflete sozinho e que um projeto avança quando a coletividade pensa sobre ele. Alarcão (2001) traz o conceito de escola reflexiva, definindo-a como uma "organização que continuamente se pensa a si própria, na sua missão social e na sua organização, e se confronta com o desenrolar da sua atividade em um processo heurístico, simultaneamente avaliativo e formativo.”

A mesma autora constata que a escola não está atendendo às demandas atuais da sociedade, sendo necessária uma mudança paradigmática. Destaca que, para isso, é necessário mudar o pensamento sobre ela, refletir sobre a vida em uma atitude de diálogo com os problemas e as frustrações, os sucessos e os fracassos, mas também um diálogo com o pensamento, o próprio e o dos outros. Para cumprir essa função, é necessária uma mudança nos métodos, no processo de aprendizagem e nos conteúdos, nos valores e nas relações humanas.

Assim, a Famema instituiu um Núcleo de Avaliação que está estruturado nos comitês de avaliação do estudante e de avaliação de processo. Este trabalho contínuo de avaliação formativa possibilita a transformação e/ou correção de rumos durante a implantação dos processos o que acaba gerando mais confiança e satisfação.

Alarcão (2001) destaca ainda o fato de que a escola não tem só o compromisso de preparar para a cidadania, mas de oportunizar a vivência desta na compreensão da realidade, no exercício da liberdade e da responsabilidade, na atenção e no interesse pelo outro, no respeito à diversidade, na correta tomada de decisões, no comprometimento com as condições de desenvolvimento humano, social e ambiental; possibilitando a participação de todos. Assim, o professor, como um ator, tem um papel a desempenhar na política educativa e sua atividade deve desenrolar-se no cruzamento das interações político-administrativocurricular-pedagógicas. E a escola, não querendo estagnar, deve interagir com as transformações ocorridas no mundo e no ambiente que a rodeia. Conclui que só a escola que se interroga, poderá mudar seu rosto.

Diante desta realidade, é preciso um posicionamento pessoal, responsável e radical do sujeito comprometido com a construção, como afirma Belloni (1999, p. 36):

[...] uma sistemática de avaliação que vise o aperfeiçoamento da qualidade da educação - isto é, do ensino, da aprendizagem e da gestão institucional - com a finalidade de transformar a escola atual em uma instituição voltada e comprometida com a aprendizagem de todos e com a transformação da sociedade em uma sociedade realmente democrática. 
A avaliação deve ser um processo contínuo e de responsabilidade de todos, uma vez que o resultado esperado é a aprendizagem organizacional e dos sujeitos. Sacristán (1998, p. 298) define que:

Avaliar se refere a qualquer processo por meio do qual alguma ou várias características de um estudante, de um grupo de estudantes, de um ambiente educativo, de objetivos educacionais, de materiais, professores, programas, etc., recebem a atenção de quem avalia, analisando-se e valorizando-se suas características e condições em função de alguns critérios ou pontos de referência para emitir um juízo que seja relevante para a educação.

A avaliação não é um fim em si mesmo, mas deve possibilitar a análise da realidade para focar as ações com a finalidade de refletir sobre a mesma na perspectiva da reconstrução da ação. Patton (2002) propõe nesta direção a ponderação avaliativa como uma forma de pensar sobre a conexão entre a ação e a reflexão.

Não se pode falar de gestão em saúde sem falar de Donabedian (1992), que desenvolveu, no início da década de 90, um quadro conceitual fundamental para o entendimento de qualidade em saúde, a partir dos conceitos de estrutura, processo e resultado. Donabedian aponta os limites dos conceitos por ele elaborados, considerando ser uma versão simplificada da realidade e que as dificuldades encontradas para a distinção entre as três categorias surgem mais freqüentemente quando são separadas do âmbito clínico para o qual elas foram desenhadas, e se tenta utilizá-las em outros tipos de avaliação. Mesmo assim, estas categorias foram e continuam sendo exaustivamente utilizadas, inclusive, atualmente nos processos de acreditação e gestão pedagógica. Na Famema, estamos utilizando os referenciais de avaliação provenientes da educação articulando com os da saúde, uma vez que o nosso desafio é desvendar a realidade dos processos de produção pedagógicos, integrados aos processos de gestão e de produção do cuidado.

\section{Conclusão}

Ao realizar esta pesquisa avaliativa do processo de gestão na implantação de processos inovadores foi possível um olhar diferenciado para a realidade do entendimento e da participação de gestores, docentes e discentes nos mecanismos de gestão, inferindo a resiliência presente em cada seguimento. Isto, constituiu-se em um potente instrumento para a melhoria e otimização gerencial. 
Os resultados apontaram fortalezas como socialização do conceito de gestão participativa e pontos que requerem atenção como a frágil comunicação interna. Isto proporciona subsídios para a readequação dos processos e serve como parâmetro para outras instituições existentes que estão vivenciando processos similares, visto que estamos em um momento político favorável na implantação de novas tecnologias de formação e gestão.

\section{Referências}

AFONSO, A. J. Avaliação educacional: regulação e emancipação: para uma sociologia das políticas avaliativas contemporâneas. 3.ed. São Paulo: Cortez, 2005.

AGUILAR-DA-SILVA, R.H.; TSUJI, H. A gestão do conhecimento em metodologisa ativas de ensino aprendizagem: uma reflexão do trabalho desenvolvido na Faculdade de Medicina de Marília. Revista Gestão e Tecnologia, Pedro Leopoldo, v. 7, n. 2, jul./dez. 2006.

ALARCÃO, I.; Tavares, J. Paradigmas de formação e investigação no ensino superior para o Terceiro Milênio. In: ALARCÃO, I. (Org.) Escola reflexiva e nova racionalidade. Porto Alegre: Artmed Editora, 2001.

BARDIN, L. Análise de conteúdo. Lisboa: Edições 70, 1979.

BELLONI, Isaura. Avaliação institucional: um instrumento de democratização da educação. Brasília, Linhas Críticas. V. 5, n. 9, p. 7-30, jul./dez. de 1999.

BRASIL. Ministério da Educação. Conselho Nacional de Educação. Parecer CNE/CES 1.133/2001, de 7 de agosto de 2001: diretrizes curriculares nacionais dos cursos de graduação em enfermagem, medicina e nutrição. [Internet]. Brasília; 2001. [citado 2005 maio 24]. Disponível em: http://www.mec.gov. br/Sesu/diretriz.shtm. Acesso em: 25 jun. 2002.

BRASIL. Ministério da Saúde. Portaria n. 198/GM/MS de 13 de fevereiro de 2004: institui a Política Nacional de Educação Permanente em Saúde como estratégia do Sistema Único de Saúde para formação e o desenvolvimento de trabalhadores para o setor e da outras providências. Brasília, 2004a. Disponível em: <http://www2.prefeitura.sp.gov.br/. secretarias/saude/legislacao/0137>. Acesso em: 14 jul. 2006. 
CAMPOS, G. W. S. Considerações sobre a arte e ciência da mudança: revolução das coisas e reforma das pessoas: o caso da saúde. In: CECILIO, L. C. (Org.). Inventando a mudança na saúde. São Paulo: Hucitec, 1994. cap. 1 , p. 29-87.

CAMPOS, A. M. O desafio de formar gestores. Momento Acadêmico COPPEAD, Rio de Janeiro: UFRJ, 1995.

CAMPOS, G. W. S . Um método para análise e co-gestão de coletivos. São Paulo: Hucitec, 2000.

CAMPOS, G. W. S. Subjetividade e administração de pessoal: considerações sobre modos de gerenciar o trabalho em equipes de saúde. In: MERHY, E. E.; ONOCKO, R. (Orgs). Agir em saúde: um desafio para o público. São Paulo: Hucitec, 1997. cap. 2, p. 71-112.

CECCIM, R.B.; FEUERWERKER, L.C.M. O quadrilátero da formação para a área da saúde: ensino, gestão, atenção e controle social. PHYSIS: Revista de Saúde Coletiva, Rio de Jsneiro, v. 14, n. 1, p. 41-66, jan./jun. 2004.

CONTRANDIOPOULOS, A. P. et al. A avaliação na área da saúde: conceitos e métodos. In: HARTZ, Z. M. A. (Org.). Avaliação em saúde: dos modelos conceituais a prática na análise da implantação de programas. Rio de Janeiro: Edit. FIOCRUZ, 1997. p. 29-47.

\section{DIBELLA, A.J.; NEVIS, E.C. Como as organizações aprendem:} uma estratégia integrada voltada para a construção da capacidade de aprendizagem. São Paulo: Educator, 1999.

DONABEDIAN, A. The Quality of Care - How Can it be Assessed? JAMA, v. 260, n. 12, p. 1743-1748, set. 1992.

GOMES, R. et al. Organização, processamento, análise e interpretação dos dados: o desafio da triangulação. In: MINAYO, M. C. S.; ASSIS, S. G.; SOUZA, E. R. (Org.) Avaliação por triangulação de métodos: abordagem de programas sociais. Rio de Janeiro: Fio Cruz, 2005. cap 6, p. 185 - 221.

HIGA, E.F.R.; ILIAS, M.; FIORINI, V.M.L. Considerações sobre o olhar de professores em relação ao processo de educação permanente na Famema.

Revista Brasileira de Educação Médica, Rio de Janeiro, v. 31, n. 2, Suplemento 1, p. 36, maio/ago. 2007. 
KIM, D.H. The link between individual and organizational learning. Sloan Management Review, Cambridge, v. 35, n. 1, p.37-50, 1993.

MINAYO M. C. S.; SANCHES, O. Qualitativo-quantitativo: oposição ou complementaridade? Cadernos de Saúde Pública, Rio de Janeiro, v. 9, n. 3, p. 239-248, jul./set. 1993.

MINAYO, M. C. O desafio do conhecimento: pesquisa qualitativa em saúde. São Paulo: HUCITEC-ABRASCO, 1992.

MERHY, E. E. et al. Agir em saúde: um desafio para o público. São Paulo: Hucitec; Buenos Aires: Lugar Editorial, 1997.

MERHY, E. E. O ato de governar as tensões constitutivas do agir em saúde como desafio permanente de algumas estratégias gerenciais. Ciência Saúde Coletiva, Rio de Janeiro, v. 4, n. 2, p. 305-14, 1999.

PATTON, MQ. Qualitative research \& evaluation methods. 3. ed. Thousand Oaks: Sage Publications; 2002.

SACRISTÁN, J.G. O currículo: os conteúdos do ensino ou uma análise prática? In: SACRISTÁN, J.G.; PÉRES GOMES, A.L. Compreender e transformar o ensino. 4 ed, Porto Alegre: Artmed, 1998. p. 119-148.

UNESCO. Educação: um tesouro a descobrir. 4 ed, São Paulo: Corte, Brasília, MEC/UNESCO, 2000. (Cap.4).

YUNES, M. A. M.; SZYMANSKI, H. Resiliência: noção, conceitos afins e considerações críticas. In: TAVARES, J. (Org.). Resiliência e educação. 2 ed, São Paulo: Cortez, 2001. 